\title{
CARLOS HILGER*
}
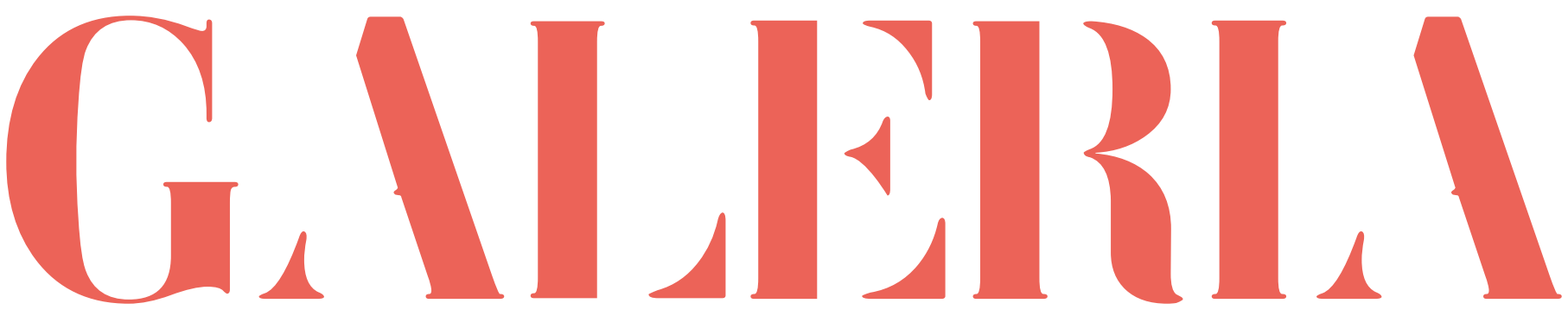

Fecha de recepción: 14 de mayo de 2018

Fecha de aceptación: 20 de agosto de 2018

Sugerencia de citación: Hilger, Carlos. 2020. Galeria Barolo: Ícono dantesco en Buenos Aires. La Tadeo Dearte 6(6), 150-167. doi: 10.21789/24223158.1416 
BAROLO GALLERY: DANTESQUE ICON IN BUENOS AIRES

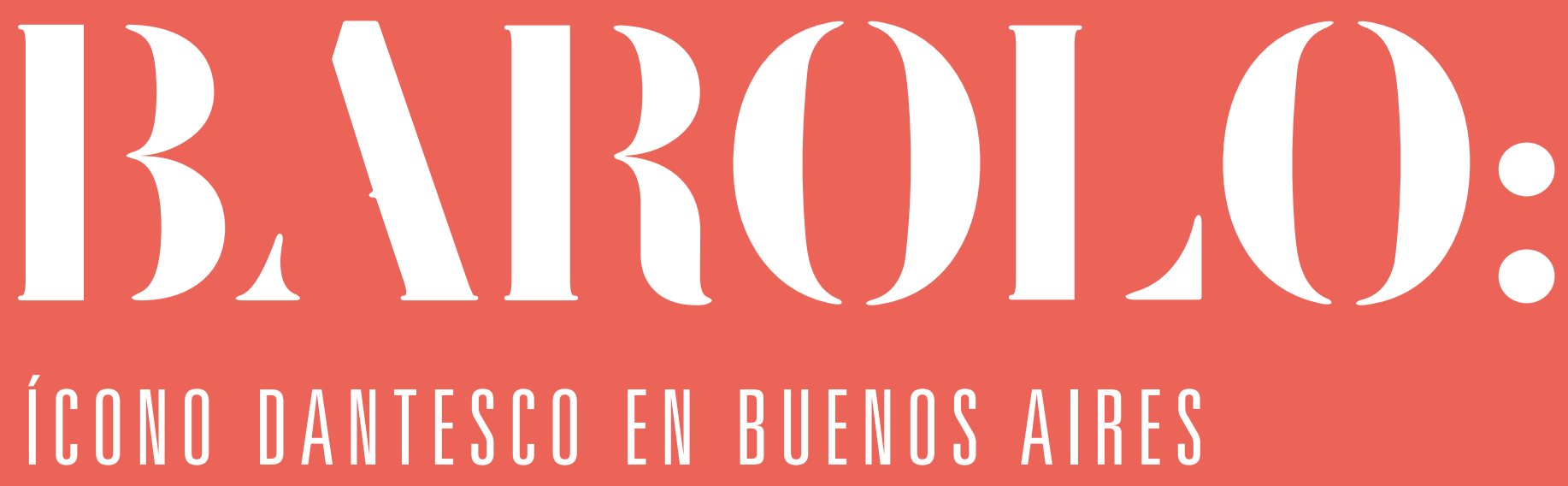

* Arquitecto, profesor e investigador de la Facultad de Arquitectura Diseño y Urbanismo Universidad de Buenos Aires, Argentina carloshilger@gmail.com 
Dante AlıghıERI le dice a Virgilio en su Divina Comedia que se siente purgando su pena en la Primera Terraza de la Montaña del Purgatorio. ${ }^{1}$ Arq. Palanti y Sr. Barolo llevaron adelante el «Monumento al Genio Latino» en el Hemisferio Austral. Soñaron que el «Pasaje Barolo» fuese el sepulcro del Dante... El Barolo oculta simbologías y sentidos. Es un «Templo bajo la Cruz del Sur», una maqueta ilustrada del cosmos, siguiendo la tradición de las catedrales góticas.

Dante AlighIERI tells Virgilio, in the Divina Commedia, that he also sees himself purging his "grief" in the First Terrace of the Mountain of Purgatory [1]. Arq. Palanti and Mr. Barolo carried out the "Monument to the Latin Genius" the Southern Hemisphere. They dreamed that the "Passage Barolo" was the tomb of Dante. The Barolo hides symbols and senses. It is a "Temple under the Cross of the South", an illustrious maquette of the cosmo, following the tradition of the Gothic cathedrals.

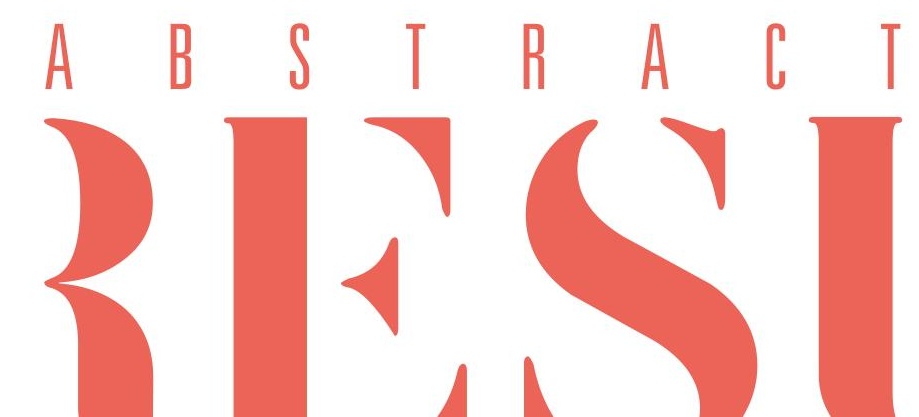





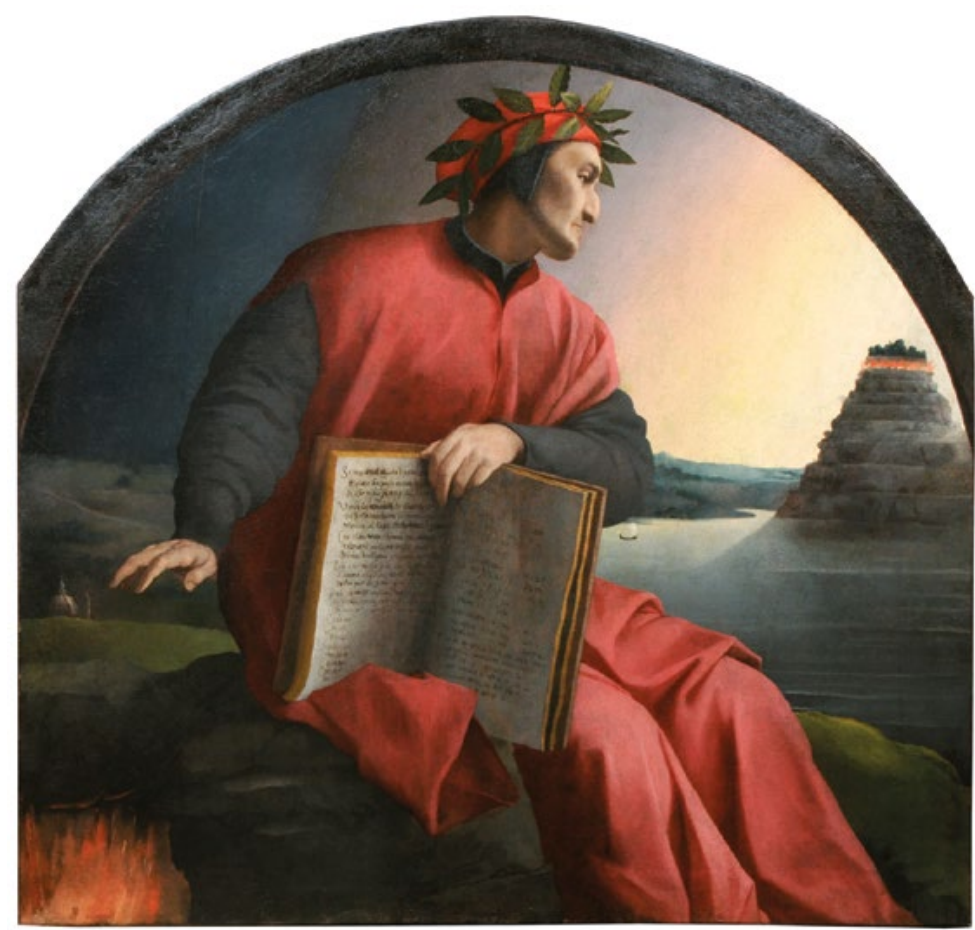

[ Figura 1. Ritratto allegorico di Dante, de Agnolo Bronzino (1530). ${ }^{3}$ ]

ACASO FUE Ulises, el griego el primero en llegar al Hemisferio Austral, al menos en la ficción. Dante Alighieri, en La Divina Comedia (Infierno, XXVI, 90, 142) relata una extraña historia, en la cual Ulises ya viejo, cansado y aburrido de su vida en Gaeta, decide emprender un último viaje con su última nave y con algunos viejos camaradas; cruza las columnas de Hércules y se dirige al sur. Una acción imprudente, una infracción a la razón, un viaje sacrílego. El hemisferio austral estaba vedado a los hombres. Un mortal podía traspasar las columnas de Hércules conducido únicamente por «la soberbia». Llegan al Hemisferio Austral después de algunos meses de navegación; divisan una montaña parda en el horizonte. Su nave da tres vueltas y a la cuarta es tragada por el mar. Ulises arderá perpetuamente en el círculo infernal de los falsarios, castigando así «su soberbia». Dante así lo condena, por sus engaños en la Guerra de Troya; la creación del «Caballo», que provocando la caída de la ciudad hizo que de Troya saliese después Eneas, noble progenitor de los romanos, también por delatar a Aquiles, ${ }^{2}$ y por el «robo del Paladio» que protegía a Troya. A Ulises, Dante le permite divisar una montaña en el horizonte, es la Montaña del Purgatorio, donde se redimen los pecados, pero no le será permitido eximir sus culpas. Es máximo castigo ver que los pecados a través del perdón pueden regenerar la sustancia. Una celeridad que le será negada, la no redención eterna en el Infierno, donde lo encuentra en la octava fosa del octavo círculo, junto a Diomedes. 
Luego del encuentro, Dante también llega al Hemisferio Austral, donde en su geografía se encuentra la Montaña del Purgatorio. Lo registra el canto noveno de la tercera parte, llamada Purgatorio, de La Divina Comedia. Dante, autor y protagonista del libro, llega a la montaña santa del Purgatorio ${ }^{4}$ acompañado por Virgilio. El Purgatorio se configura como un tercer lugar en el más allá en la geografía dualista del otro mundo: infierno y cielo. Desde los primeros siglos, los cristianos creyeron confusamente en la posibilidad de redimir algunos pecados tras la muerte; hubo que esperar al final del siglo XII para que apareciera el «Purgatorium»; el Segundo Concilio de Lyon (1274) le otorga una formulación oficial en la Iglesia latina. La tierra, en la geografía de Dante, es una esfera inmóvil en el centro del cosmos. En la antigüedad, era un hecho aceptado la esfericidad de la tierra; figuraba en las antiguas cosmogonías griegas y formaba parte del sistema que Aristóteles ${ }^{5}$ elaboró en el 330 antes de Cristo, y que se reflejan en los escritores cristianos cuyos trabajos evidenciaban claramente la convicción de esfericidad que la Tierra como en el Benedictino San Beda «El Venerable»; en sus escritos en inglés antiguo, hacia el año 700. Dante mezcla a Aristóteles con el conocimiento geográfico del 1300 para elaborar la arquitectura de su poema. La geografía era muy importante para ubicar la montaña del Purgatorio, ya que esta se encontraba en las antípodas de Jerusalén. ¿Dónde se encontraban las antípodas según el conocimiento de Dante?

Ya en el siglo III a.C., Eratóstenes había calculado correctamente la circunferencia de la Tierra utilizando geometría simple y estudiando las sombras proyectadas por los objetos en dos lugares diferentes: Alejandría y Siena (el actual Asuán). Estas mediciones fueron ampliamente conocidas entre los estudiosos, pero la confusión sobre las antiguas unidades de distancia en que se expresaban había llevado, en la época de Dante incluso, hasta la época de Colón que comete el mismo error, a un cierto debate sobre el tamaño exacto de la Tierra.

En la Florencia de Dante la estimación del diámetro de la Tierra era la de Alfraganus, ${ }^{6}$ de un grado de latitud, pero él no se dio cuenta de que esto se expresaba en la milla árabe en lugar de la milla romana más corta con la que él estaba familiarizado, de lo que resulta un diámetro del Globo
Terráqueo en el que las antípodas de Jerusalén sería (según la geografía actual: $33^{\circ} \mathrm{S} 69^{\circ}$ ) los Andes entre Argentina y Chile.

La triple arquitectura de La Divina Comedia ${ }^{7}$ está constituida por Infierno, Purgatorio y Paraíso; depresión y una montaña son los principales accidentes de la esfera terrestre. En la depresión el Infierno, el Purgatorio en las laderas de la montaña. En el centro del hemisferio boreal, el único permitido a los hombres, está la Montaña de Sion. El hemisferio austral es de agua y ha sido vedado a los hombres; en el centro hay una montaña opuesta a la de Sion: es la Montaña del Purgatorio.

Bajo la Montaña de Sion, pero mucho más ancho, se abre hasta el centro de la tierra un cono invertido: el Infierno, dividido en nueve círculos decrecientes, como gradas de un anfiteatro; en el centro, Lucifer. Una grieta que abrieron en la roca las aguas del lago Leteo comunica el fondo del Infierno con la base del Purgatorio. En la ladera del Purgatorio se escalonan siete terrazas, que significan pecados mortales. El Edén ocupa su cumbre. Giran en torno de la tierra nueve esferas concéntricas: los nueve círculos de Ptolomeo. Las siete primeras son los cielos planetarios: Luna, Mercurio, Venus, Sol, Marte, Júpiter, Saturno (la Luna y el Sol eran considerados planetas); ${ }^{8}$ la octava era el Cielo de las «Estrellas Fijas» dividido el Zodiaco, ${ }^{9}$ la novena era el «Cielo Cristalino» y las demás constelaciones, rodeado por el Empíreo; es el sitio de la presencia física de Dios, donde residen los ángeles y las almas acogidas en el Paraíso; no estaba limitado espacialmente ni constituido de materia, como sí las otras regiones. Sitio espiritual, fuera del tiempo y del espacio. Mientras los nueve cielos están en continuo movimiento, el Empíreo se encuentra eternamente inmóvil. La Tierra es como un péndulo con el hemisferio norte hacia abajo y el sur hacia arriba; su cielo está precedido por la constelación «La Cruz del Sur» (Purgatorio 1, 22, 27) constelación visible únicamente desde el Hemisferio Austral. Allí se ubica la entrada de los cielos, así como se entra al Infierno por debajo de Jerusalén. Sobre esta constelación de la Cruz del Sur florece una rosa inconmensurable, alrededor de un punto que es Dios. Un sistema metafísico de raíz platónica, que juzgó como el cuerpo más perfecto a la esfera, es el que dicta la morfología de los mundos recorridos por Dante. 


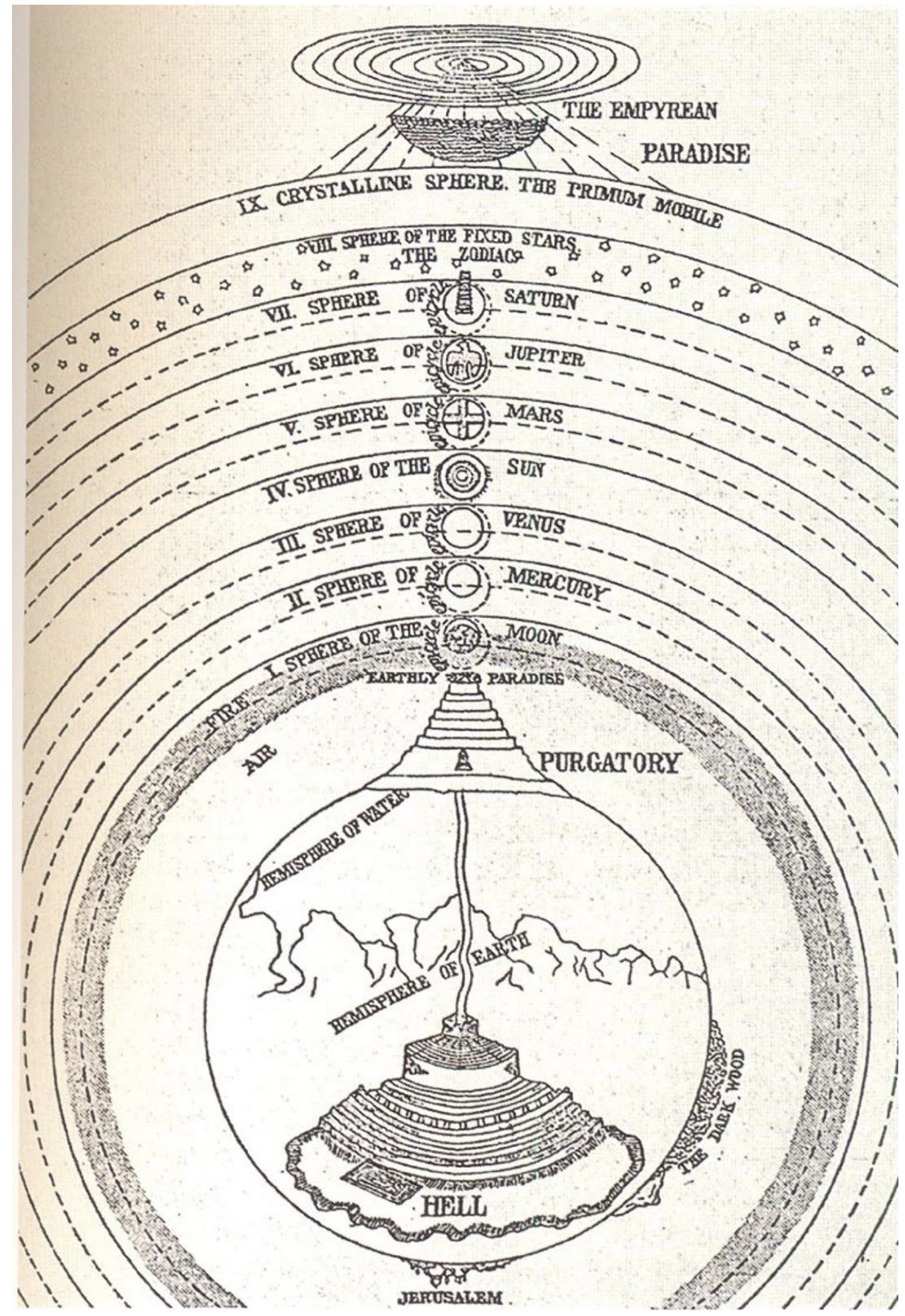

[ Figura 2. Cosmovisión de La Divina Comedia, dibujo y collage basado en esquemas de Riccardo Guerri. ${ }^{10}$ Izquierda: Dante y Virgilio escuchan el Canto 26 de Ulises, que relata su llegada a la Montaña del Purgatorio. Derecha: Dante señala el lugar de la montaña que identifica con su pecado a purgar. ] 
[ Figura 3. Giorgio Vasari, Seis poetas toscanos (De derecha a izquierda: Cavalcanti, Dante, Boccaccio, Petrarca, Cino da Pistoia y Guittone d'Arezzo. Pintura al óleo (1544). ${ }^{11}$ ]

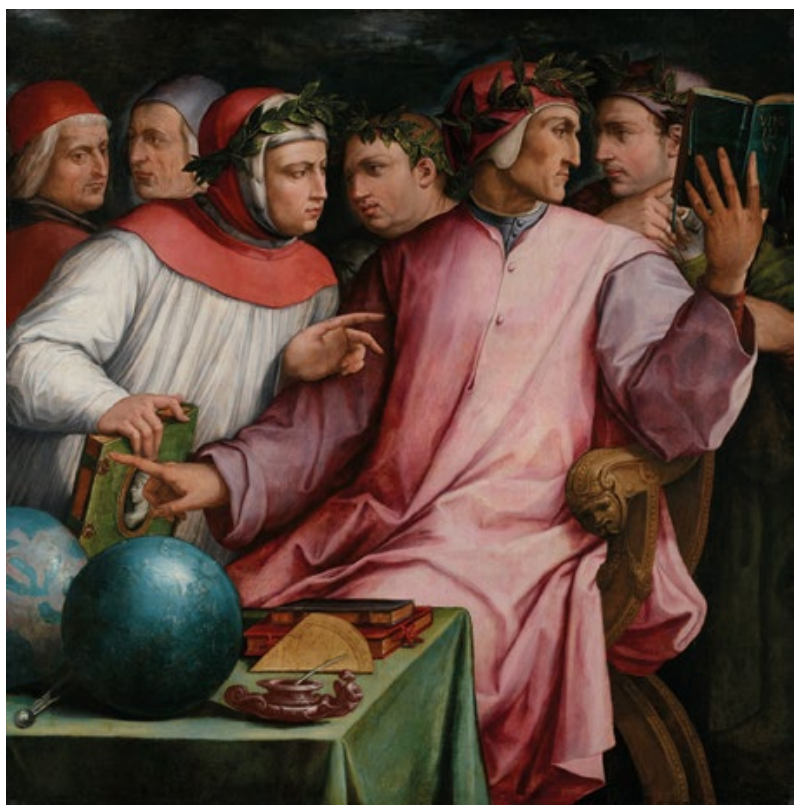

Asín Palacios ${ }^{12}$ encuentra un viaje similar en Mahoma; desciende a regiones infernales (Isra) y luego asciende a las esferas celestiales (Miraj). Existen múltiples relaciones de contenido y de forma entre La Divina Comedia y el Kitab El-Isra (libro del «Viaje Nocturno» de Mahoma) escrito por Mohyiddin Ibn Arabi, apodado El-Andalusi debido a que nació y vivió en España, ochenta años antes que el de Dante, y es para el Islam el más grande de los maestros espirituales (Es-Sheikh El-Akbar). Ambos libros contienen una descripción de la geografía del más allá.

Desde mediados del siglo XIX y gran parte de la primera mitad del siglo XX, el resurgimiento del gótico engendró un vasto repertorio de formas y actitudes medievalistas, que significaban la garantía de la generación de una nueva comunidad. El espíritu gótico del arte unificado influyó en Morris, Taut, Behrens, Gropius y Wright. Motivaba búsquedas metafísicas y unificaba a los artistas en hermandades espirituales, como los prerrafaelistas en Inglaterra, seguidos por los Arts and Crafts, la comunidad de Darm Stadt, la comunidad del desierto de Wright, la cadena de cristal de Taut, los Rosecroix de Péladan, la Bauhaus, los Terciarios franciscanos de Barolo. La ilusión de transformar la vida y la sociedad mediante la arquitectura era una tradición heredada del espíritu constructivista gótico y sus cofradías y hermandades. Pero era un gótico inventado por la imaginación tardo-romántica, que no era una resultante de la historiografía.

En ningún momento Europa estuvo tan cerca de Oriente como durante el gótico. «El gótico no era sino un sueño maravilloso de Oriente, soñado por los cruzados a su vuelta», decía Adolf Behne. Gropius incitaba a construir siguiendo al "gótico-indio». Como los modelos más elevados de la construcción enlazaban en un gesto ultra eclécticos con tipologías hinduistas $y$, a veces, con mezquitas musulmanas. Creían que estos templos eran el resultado de la hermandad del hombre materializada por las fraternidades y sociedades secretas. La edificación de la catedral de cristal era para Taut la autoedificación del hombre mismo. Oriente, islam, gótico e India representaban lo irracional, lo dionisíaco para la cultura de principios de siglo. Muchos autores presentaron la cultura griega como racionalista. Nietzsche y Burckhardt se oponían a esta condición y destacaron el carácter dionisíaco y por lo tanto irracional de esta cultura. Ciertos autores como Schopenhauer, Bergson y Spengler describen al cosmos como manifestación de algo irracional que además trasciende el conocimiento, o al menos la razón. La intuición, la voluntad, el impulso, el inconsciente, la visión profética, la sublimación, la purificación allanan la inconmensurabilidad entre conocimiento y realidad. El expresionismo alemán significó un renacimiento de la tradición constructivista gótica. Estaba muy de moda proponer templos laicos que convocaran a la hermandad del hombre, a la fraternidad y al amor universal.

Palanti se había formado en la Universidad de Brera bajo los estigmas de esta cultura, en Milán. Su mayor influencia en arquitectura fueron los hermanos Gino y Adolfo Coppedè. ${ }^{13}$ Fue firme militante del nacionalismo Italiano y propagandista de esa ideología ${ }^{14}$ en su arquitectura, mientras que Luis Barolo, el promotor de la construcción del Edificio denominado «Galeria Barolo» (Retomando la tipología de Galleria Vittorio Emanuele II de Milano) adhirió al nacionalismo de Gabriele D'Annunzio. ${ }^{15}$

Llega a Buenos Aires en 1909. Trabaja con el arquitecto Prins en un proyecto que es la "Facultad de Derecho», actualmente la Facultad de Ingeniería de Las Heras y Azcuénaga. La diseñan en estilo gótico con forma de «catedral cristiana», que homenajeaba la igualdad del hombre a través del derecho canónico. 

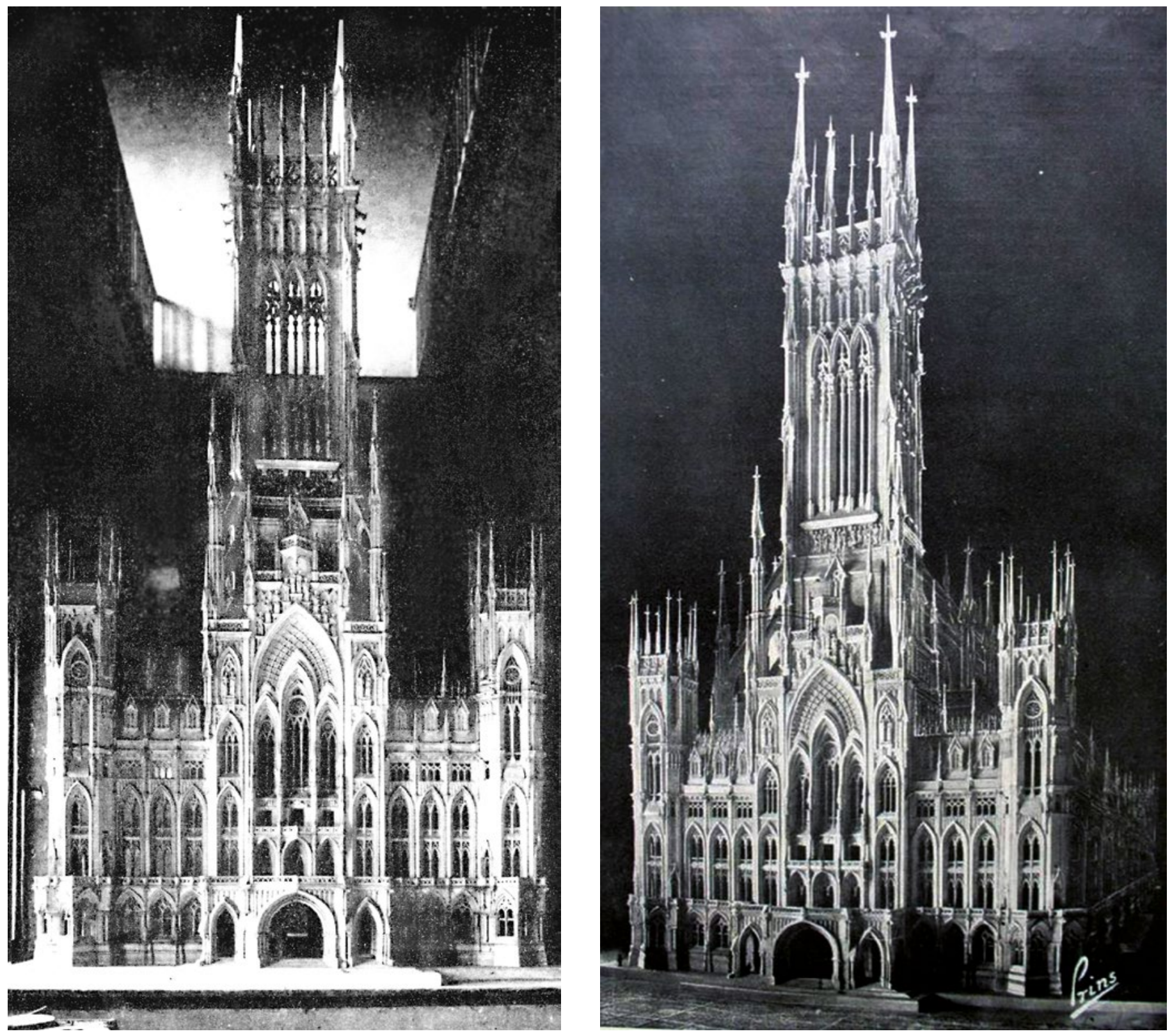

[ Figura 4. Templos proyecto Facultad de Derecho, actual Facultad de Ingeniería. Palanti, como colaborador: Arturo Prins. ]

Desde su llegada diseña una variedad muy extensa de templos y sepulcros, propuestas que realiza sin un cometido específico y que expondrá y publicará en sus libros. Templos ${ }^{16}$ a la voluntad, otros al héroe latino. 
Dante, se sabe, pertenecía a una fraternidad medieval, la Orden Terciaria Franciscana, al igual que Giotto y Colón, ${ }^{17}$ y que Palanti. Tal como se muestra el frontis de la Iglesia de San Francisco en la Ciudad de Buenos Aires.

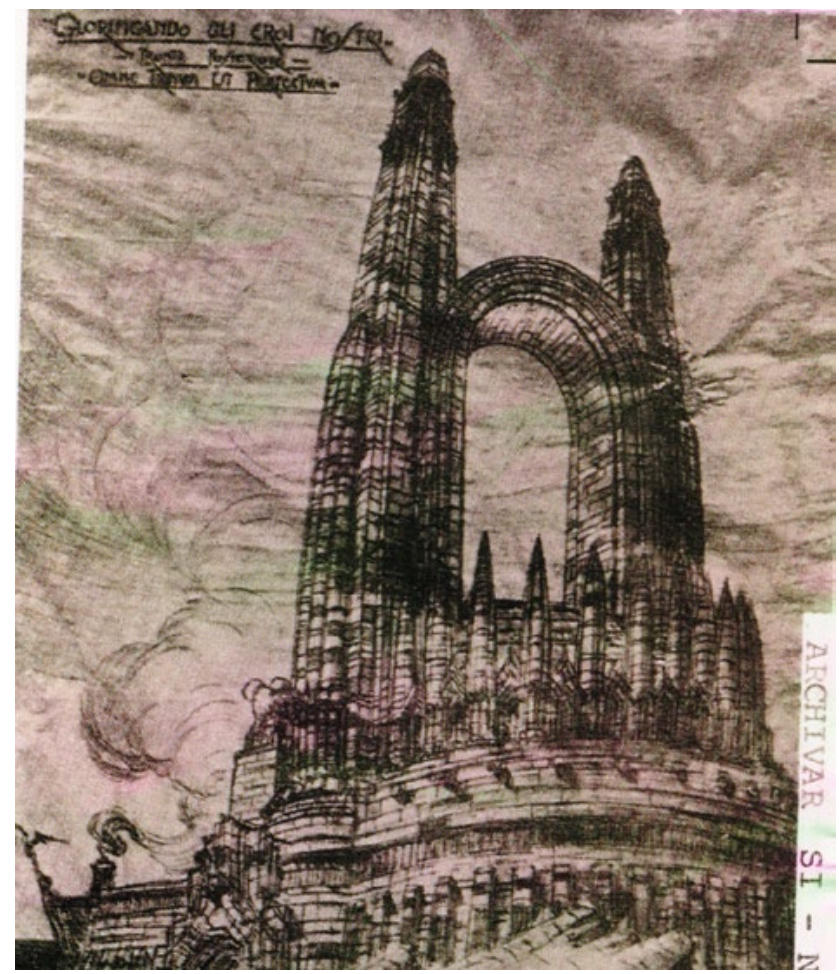

[ 1910 estudio para un templo votivo. ]

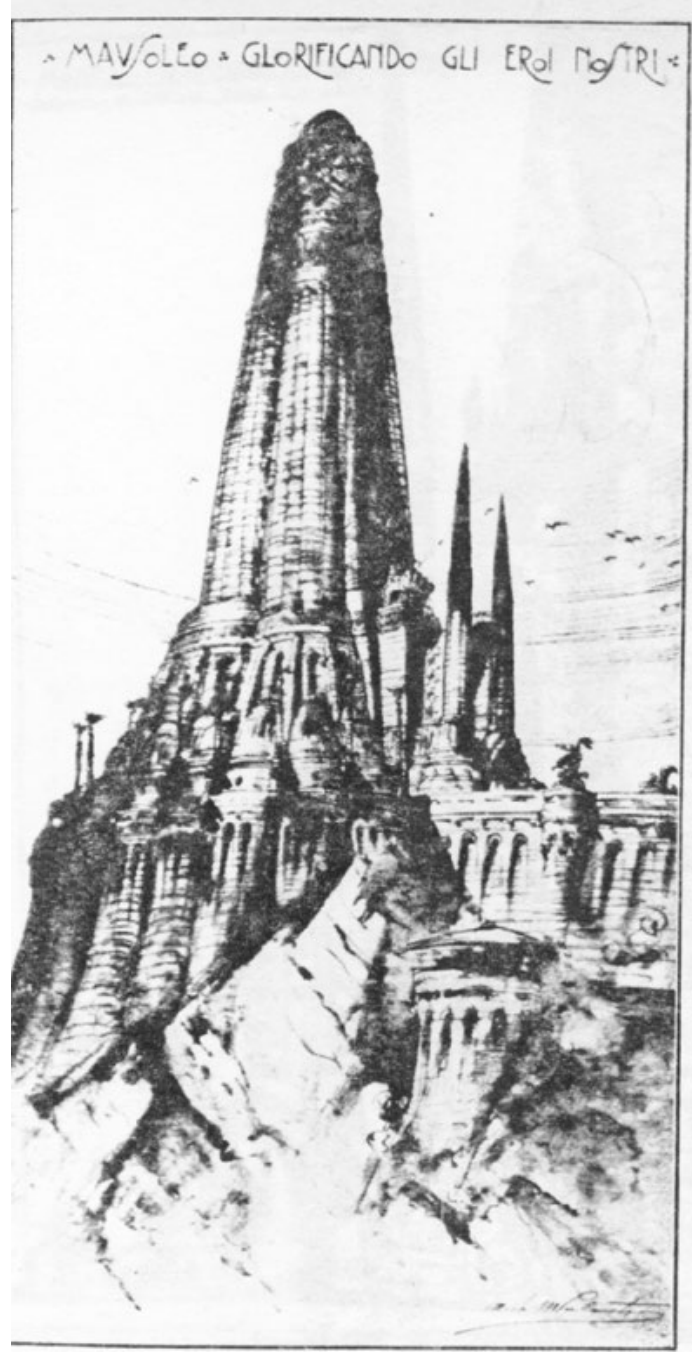

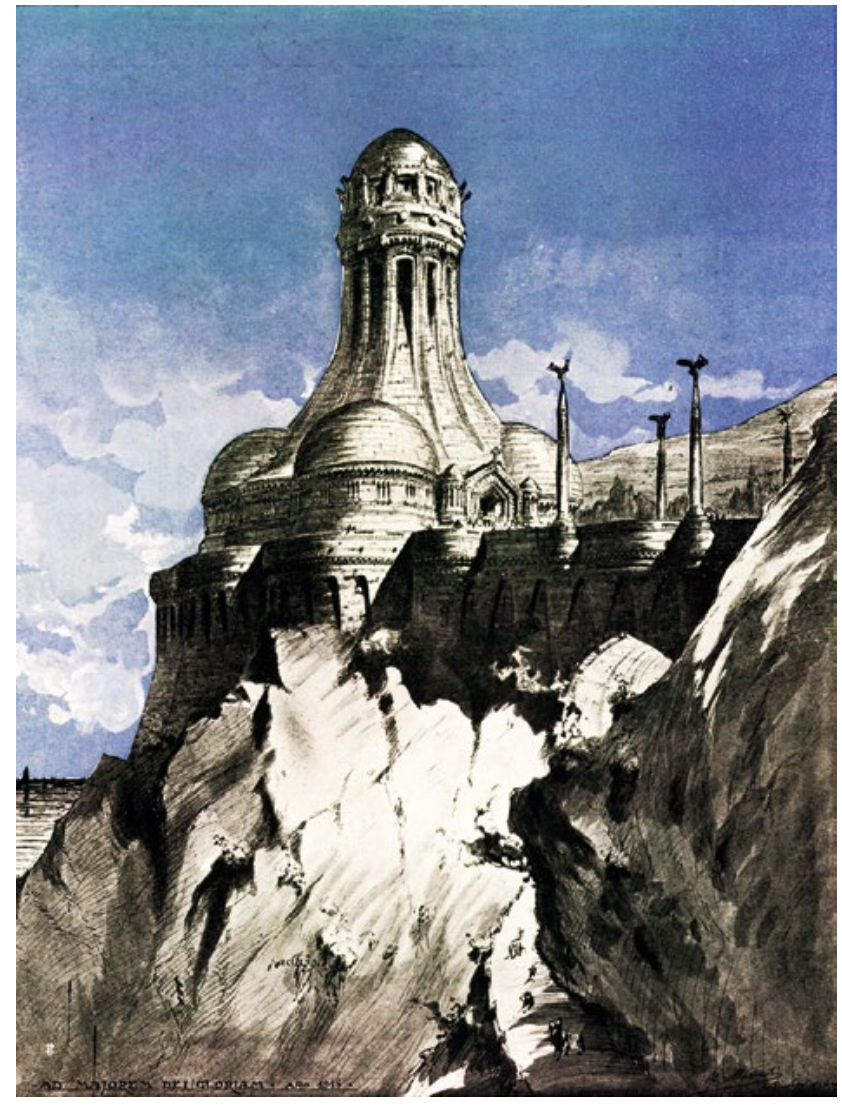

[ 1909 Templo a la paz universal. ] 


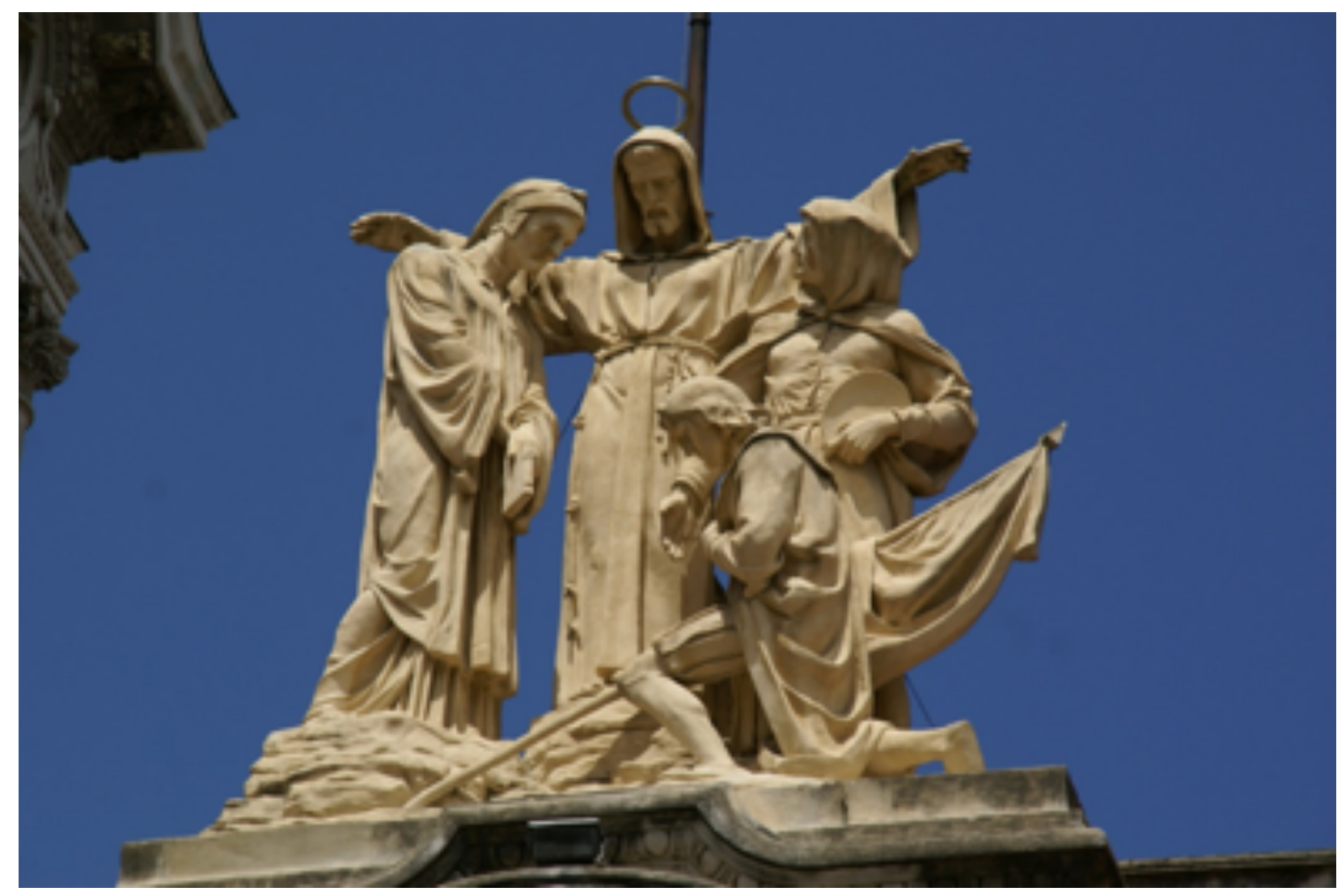

[ Figura 6. San Francisco en Buenos Aires (al centro, a su diestra Dante Alighieri, del otro lado, Giotto ${ }^{18}$ y, arrodillado, Cristóbal Colón). ]

Esta hermandad, que perdura hasta nuestros días, venera la figura de Dante como «obispo terciario» ${ }^{19}$ de la misma y difusor de la metáfora moralizante del Infierno, Purgatorio y Paraíso, que mostraba tres modos de ser de la humanidad: vicio, virtud, perfección. Los vicios y virtudes no son más que múltiples manifestaciones del amor, de la libido, del eros de Platón, con sus extravíos y debilidades que jalonan el camino del conocimiento sobre la esencia de las cosas y el engaño de las apariencias.

Palanti viene a las tierras del Purgatorio con un encargo "constructivista»: desarrollar un «Templo bajo la Cruz del Sur», un Templo en el eje ascensional de las almas, celebrando el VI Centenario de la revelación de Dante (y también de Virgilio). ${ }^{20}$ No tenía medios materiales para construirlo; solamente a través de la voluntad y de la fe debía hallar el camino constructivo. Hace varios intentos: un templo votivo, una catedral para Buenos Aires (236 metros de altura), sepulcros y monumentos dantescos escatológicos (creencias y doctrinas relacionadas con la vida de ultratumba). 

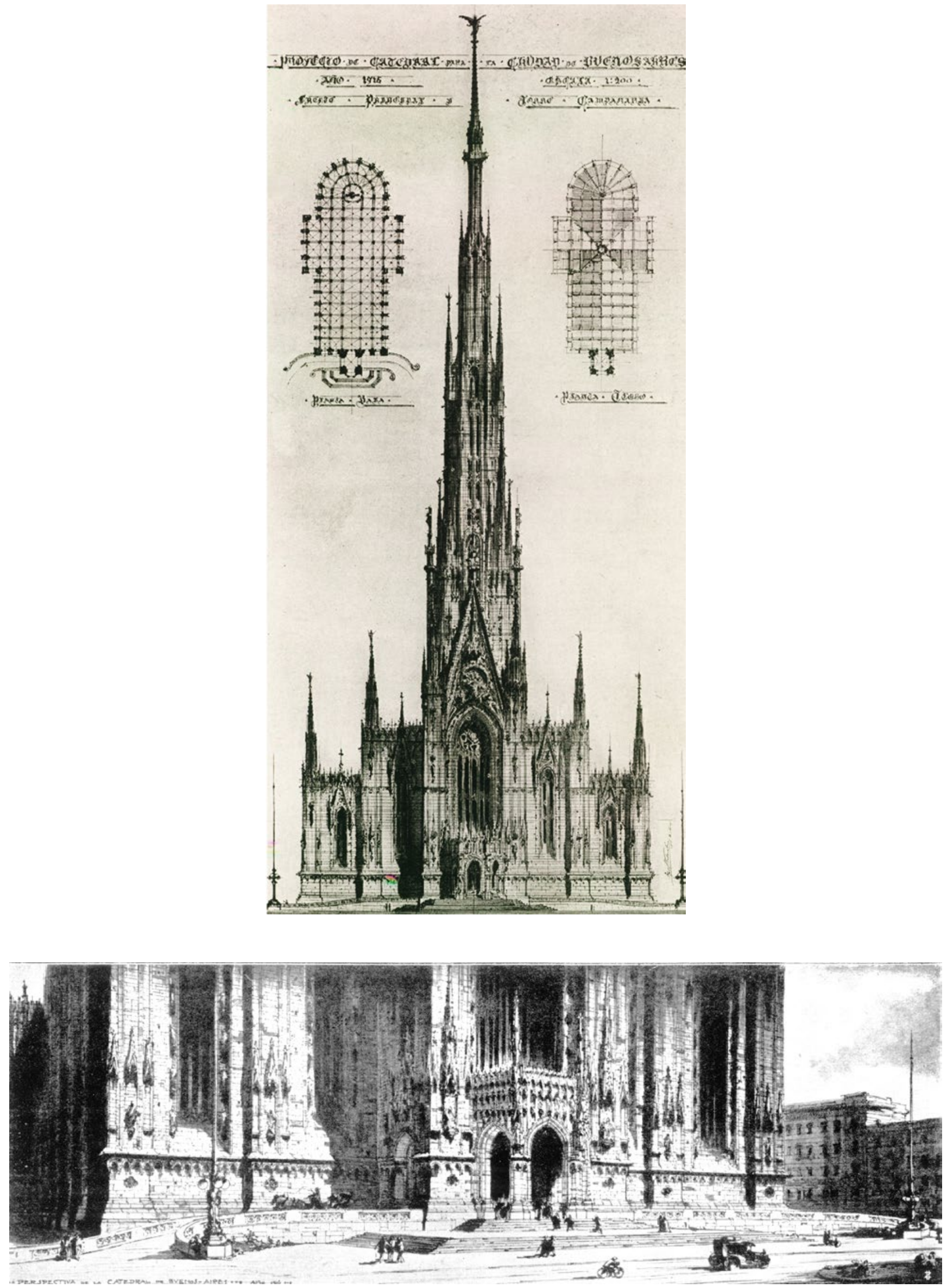

[ Figura 7. Proyecto para la Catedral de Buenos Aires por Mario Palanti. 
Después de algún tiempo en Buenos Aires, Palanti encuentra a Luis Barolo, un italiano que había llegado en 1890 y que instaló unos telares de tejido de punto. Proveyó al ejército italiano de frazadas durante la Primera Guerra Mundial, sus casimires adquirieron una difusión extraordinaria y paulatinamente el éxito coronó sus esfuerzos. Él financió la construcción la «Galeria» que lleva su nombre. El edificio es una maqueta ilustrada del cosmos, siguiendo la tradición de la catedral gótica. La catedral era concebida como el opus supremo de la albañilería de la Edad Media; el templo era la traducción en piedra de los Testamentos; debía ser capaz de oponerse a los tiempos y a las multitudes, con el fin de preservar el conocimiento, preservar las «Artes Liberales», ${ }^{21}$ siendo así un edificio dedicado solamente a oficinas de profesionales, que está abierto durante el día y cierra cada noche. Cada elemento constitutivo del templo tenía que hacer alusión a un símbolo, por eso la puerta de la Catedral de París es una tabla de iniciación en la alquimia, la de Chatres un manual astrológico. Esto no era raro; en esa época Gaudí hace la misma operación en La Sagrada Familia. También Rudolf Steiner, Vladimir Tatlin y E.L. Boullée construyeron edificios que representaban el cosmos y, en particular, Terragni proyectó en la década del 30 el Danteum sobre el Foro Romano, ${ }^{22}$ estructurado de la misma forma que el Palacio Barolo, de acuerdo con la forma y métrica de la cosmovisión de los reinos del más allá.

Palanti deja dicho que esto es un templo en las inscripciones del techo: la frase «Vt porter nonen elvs coran gentibus» («para que lleve su nombre ante los gentiles»). En la literatura bíblica más antigua, Yahvé es un típico "guerrero divino» del Cercano Oriente, que lidera el ejército celestial contra los enemigos de Israel; luego se convirtió en el principal dios del Reino de Israel (Samaria) y de Judá. Al final del exilio babilónico (siglo VI a.C.), se negó la existencia misma de dioses extraños y Yahveh fue proclamado como el creador del cosmos y el verdadero dios de todo el mundo. Con el Templo de Salomón promovieron a Yahveh como el dios de todo el cosmos. Palanti hace referencia en esta frase al templo de Salomón edificado en Jerusalén y que es modelo de toda construcción para el cristianismo, el islam y los hebreos. David no pudo edificar una casa a nombre de IHVH, su dios, a causa de las guerras que lo tenían ocupado. Llegada la paz bajo el reinado de su hijo Salomón, encaró la construcción de una casa al nombre de IHVH (Dios), según las formas y números dictados por IHVH a David. Cuando ese templo existía, el nombre de Dios (IHVH) era pronunciado una vez al año por el sumo sacerdote en el Santasantorum del templo. Al destruirse el templo de Salomón por los romanos, el nombre no se puede pronunciar; sí se podía escribir. Esta trasgresión partió el nombre en dos. Las dos primeras letras se separaron de las dos últimas y se buscan eternamente, errando por el cosmos. Las dos primeras $(\mathrm{IH})$ son un ser insensato que sueña y se piensa sin conocerse; las dos últimas (VH) son un ser afeado por la concupiscencia de lo sensible, en exilio.

La obra de Palanti fue reunir el nombre en lo que se denominada Obra Marial. Así pues, para poder reunificar las dos partes del nombre, construye un templo donde se unen cielo y tierra, bajo la Cruz del Sur, en una ciudad con nombre mariano: Santa María del Buen Ayre, hoy Buenos Aires. Esta dualidad está representada por los dragones (uno macho y otro hembra) que delimitan esta bóveda y representan también los principios alquímicos. Son las serpientes que los antiguos egipcios pintaron en círculo mordiéndose la cola para significar que procedían de la misma cosa; son las dos serpientes enviadas por Juno; son las dos serpientes del Caduceo de Mercurio; son la regeneración del individuo a través de la alquimia.

Asimismo, Palanti escribe allí: «Fundata est supra firman petran» ("está fundado sobre sólida piedra»). El templo es la envoltura del nombre. Etimológicamente, la palabra «templo» deriva de tallar - los antiguos constructores eran talladores-, que significa además autoconstrucción. «La piedra bruta ha de ser tallada». Piedra para los cristianos es Pedro, el fundamento de la Iglesia. «Sobre esta piedra fundaré mi Iglesia» (San Mateo $16,19)$. Palanti promete que su obra nos lleva al conocimiento del nombre secreto y el nombre nos liga con la perpetua creación y su sonido: el orden perfecto. El Barolo está construido en planta y secciones sobre la base de la sección áurea y el número de oro, proporciones y medidas de origen sagrado. El Templo de Salomón había sido construido de acuerdo con este número dictado por Dios a David. Para Palanti el número estaba curado en La Divina Comedia (hay semejanzas entre el Danteum de Terragni y el Barolo en cuanto a tratar de representar la cosmovisión dantesca). ${ }^{23}$ 

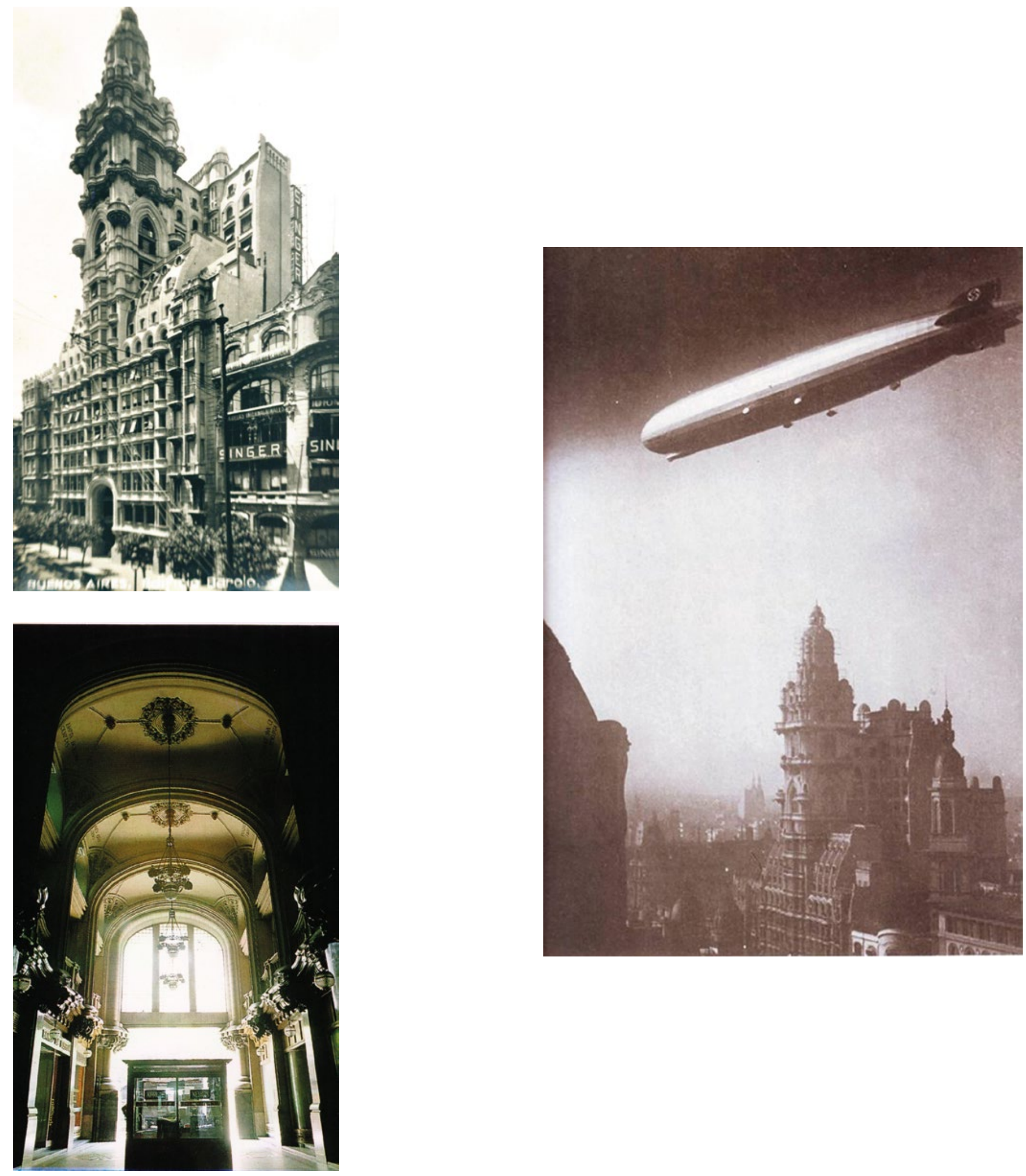
La división general del edificio y del poema es ternaria: Infierno, Purgatorio y Cielo. El número de jerarquías infernales es el nueve; nueve son las bóvedas de acceso al edificio que representan pasos de iniciación, cada uno enumerado y descrito con frases en latín en cada bóveda. Estas frases tienen distinto origen: el Testamento, Ovidio, Horacio, Virgilio, Palanti. El número siete son las divisiones del Purgatorio y de la torre del Barolo, que lo representa. Dante no se propuso establecer la Verdadera topología del otro mundo. El Purgatorio es tan irreal como la montaña en que Dante lo ubica. Palanti no representa los nueve cielos sino a través de la puerta, que es el faro de 300000 bujías; sobre él, la constelación de la Cruz del Sur: la entrada de los cielos, que se la puede ver sobre el Barolo en los primeros días del mes de junio a las 19:30 alineadas con su eje. Cien son los cantos de La Divina Comedia, cien metros la altura del Pasaje. La mayoría de los cantos comprende once o veintidós estrofas; los pisos del edificio están divididos en once módulos por frente, veintidós módulos de oficinas por bloque; la altura es de veintidós pisos: catorce de basamento, siete de torre, un faro. Estos números representan para la naometría tradicional símbolos sagrados. 22/7 es la expresión aproximativa en números enteros de la relación de la circunferencia con su diámetro; el conjunto de estos números representa el círculo, la figura más perfecta para Dante como para los pitagóricos. El número veintidós representa los símbolos de los movimientos elementales de la física aristotélica. Ademas $99+$ I es el total de nombres de Dios (cien cantos de la Comedia, cien metros de altura del edificio).

Dante murió en Ravena el 13 de septiembre de 1321. Pocos días antes había terminado los últimos versos del Paraíso, culminando la Comedia. Llevaba veinte años de exilio político de su ciudad, Florencia, que lo había deportado, despojado de sus bienes, declarado traidor. En una de sus últimas cartas maldice a sus conciudadanos y en su Infierno coloca más florentinos que habitantes de cualquier otra ciudad. La Iglesia mantuvo reticencias hacia él por siglo y medio. El cardenal Poggetto ${ }^{24}$ quemó algunos libros de Dante por heréticos y pidió que sus cenizas fueran desenterradas y dispersadas, indignidad máxima para su época que pudo ser evitada por sus amigos. Medio siglo después, Boccaccio ${ }^{25}$ reivindicó al poeta, creando la Cátedra de estudios Dantescos, por lo que Florencia ${ }^{26}$ se arrepiente de sus agravios al poeta después de cincuenta años y comienza a reclamar a Ravena sus restos para instalarlos en Santa María dei Fiori, reclamo desoído por Ravena durante más de dos siglos. El Papa florentino León $\mathrm{X}^{27}$ pone fin a la disputa el 11 de marzo de 1513, quien autorizó la mudanza, exigiendo el cadáver de Dante, para el cual Miguel Ángel construiría un sepulcro. Ravena no puede desobedecer al Papa y acepta abrir la tumba. El cadáver no estaba. Ravena explica la desaparición diciendo que el poeta estaría haciendo lo que hizo cuando vivo en su Comedia: trajinar por Cielo, Infierno y Purgatorio, destino sobrenatural del poeta. Los restos desaparecen durante tres siglos, hasta 1865. Cerca de la fecha en que Italia se proponía celebrar el sexto centenario del nacimiento del poeta, reaparecen en las cercanías de un convento medieval en Ravena, junto al cadáver, dos cartas fechadas en 1677 donde el prior Antonio Santi atestigua que son los restos de Dante y que habían sido sustraídos y ocultados para impedir el traslado por parte de León X a Florencia. Esta congregación guardó secretamente el cadáver durante todo ese tiempo. Aún hoy en día es un misterio dónde permaneció sepultado durante esos años. En los años siguientes siguen apareciendo en Ravena; ${ }^{28}$ los frailes $^{29}$ decidieron esconderlos en una puerta amurallada del oratorio adyacente del Convento de Braccioforte. En 1865, cuando un albañil, con la restauración el convento, accidentalmente descubrió bajo una puerta amurallada una caja de madera con inscripciones en latín firmado por un cierto fraile Antonio Santi (1677), quien informó que los huesos de Dante estaban contenidos en la caja. Se encontró un esqueleto «casi intacto». También el sepulcro en el Templo de Morigia, que se encontró vacío, a excepción de tres de la «falange del Poeta», y el mito dice que estaban dentro de la estatua de Mario Palanti, que fue robada en Mar del Plata. Se habían juntado demasiados huesos aún para un poeta tan ilustre. Cercana la fecha del sexto centenario de su muerte, el Gobierno italiano estaba reconstruyendo el cadáver en una operación universal a cargo de caballeros prestigiosos y de dos eminencias: «l'antropologo dell'Università di Bologna», Fabio Frassetto y su colega Giuseppe Sergi de Roma, quienes, expurgando piezas espurias y detectando infames contrabandos de huesos de conejos y otros animales, terminaron su trabajo en 1921.

Palanti y Barolo trataron de terminar el Pasaje para esa fecha: el «monumento al genio latino» en América. Su sueño no terminó allí; así como la catedral era sepulcro de prohombres de su época, soñaron que el Pasaje fuera el «Sepulcro Definitivo» del Dante, el lugar donde Dante mismo hubiera preferido descansar, el Purgatorio, precediendo el eje de ascensión de las almas al Paraíso, pasando por la Constelación de la Cruz del Sur.

Por tal motivo, Palanti diseña la escultura Ascensión, inspirada en bocetos del Sepulcro de Dante de Miguel Ángel, para ser colocada en el axis ascensional en la cúpula central del Pasaje Barolo. 


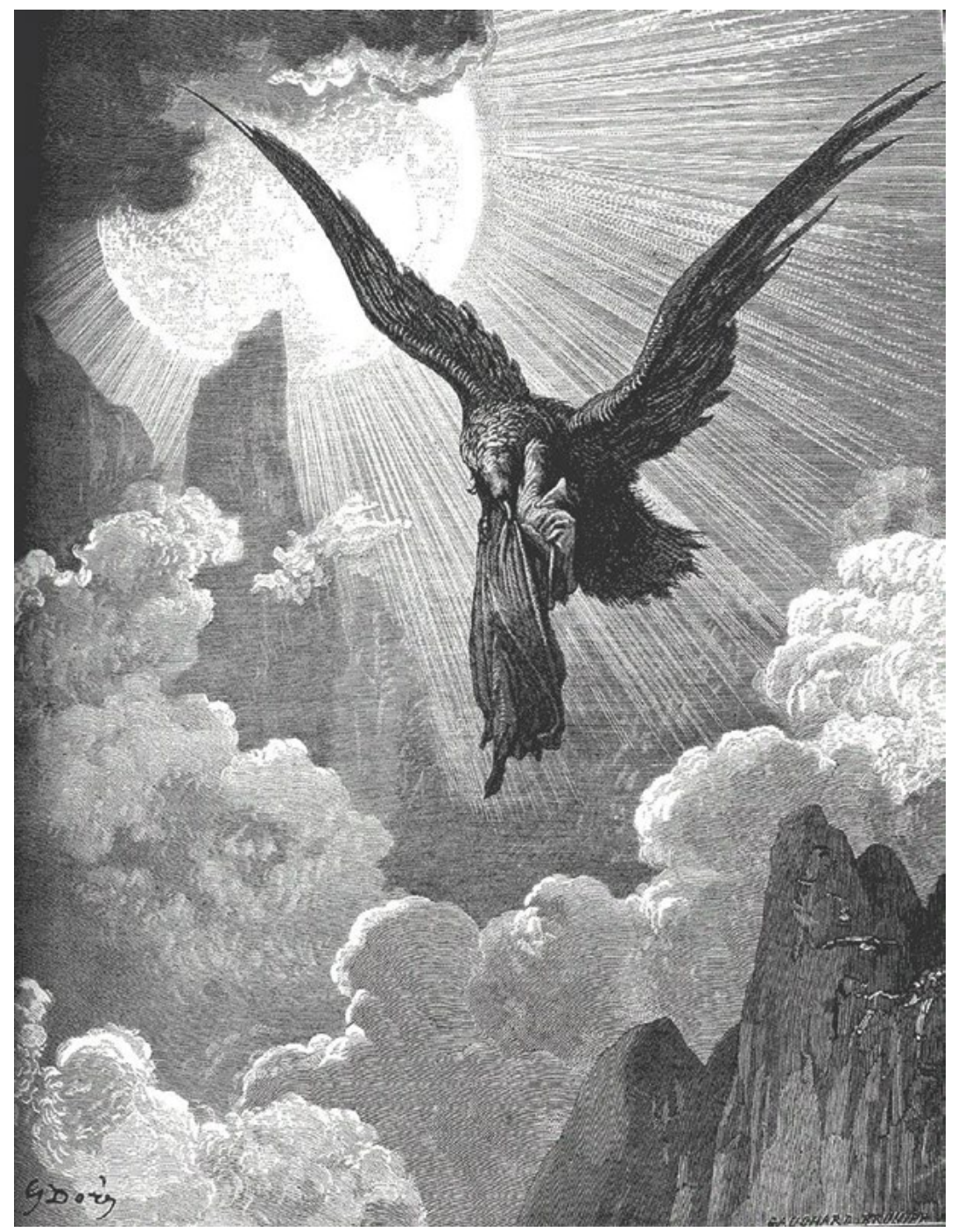

[ Figura 9. Juego de semejanzas: El Águila, obra de Gustav Doré, 1868. «Y me arrebató ascendente hasta el fuego» (Purgatorio, 29, 30). ]

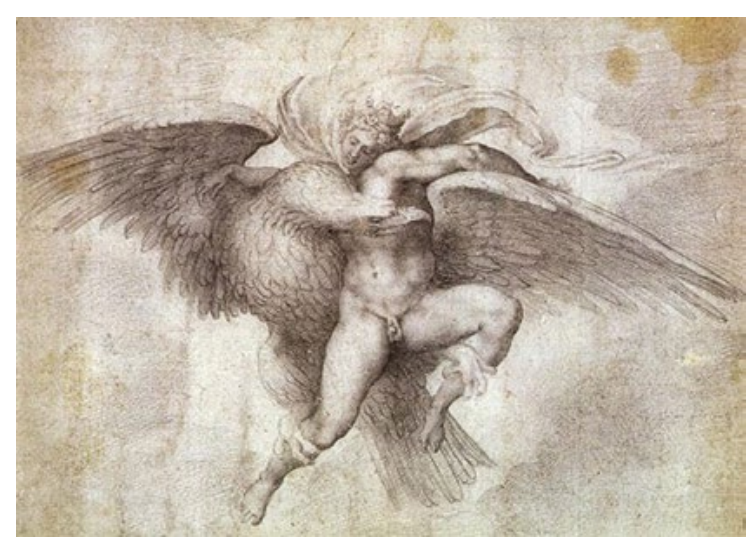

[ «Ganimedes» dibujo de Miguel Ángel que inspira a la tumba Mario Palanti, 1914. ]

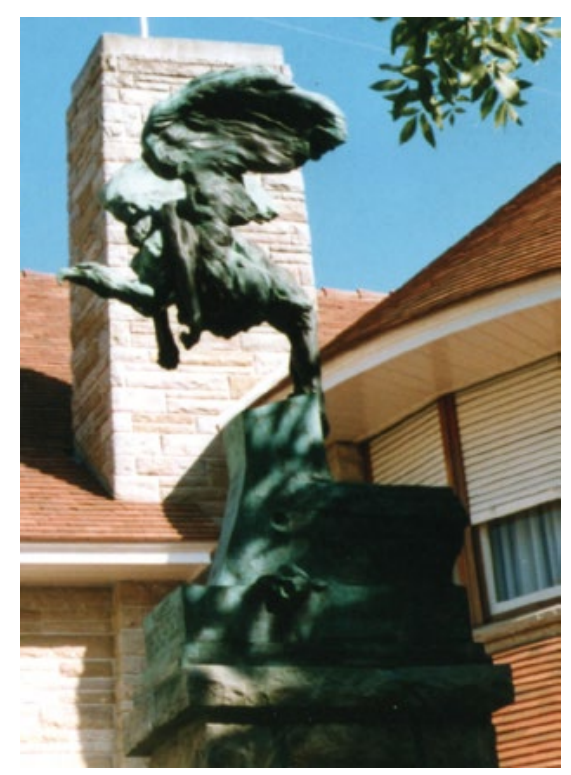

[ Escultura realizada por Palanti para colocar en el axis-mundi del Barolo. Emplazada en Güemes 2432, Mar Del Plata (Recientemente fue robada). ]

Palanti buscaba las mismas respuestas que buscamos todos. Soñó con la dicha y jugó con la ficción de encontrarla, pero le ocurrió lo que suele ocurrir con los sueños... flotaban más allá de lo expresable y lo inexpresable. El edificio se cernía sobre el universo, sobre la nada. No obstante, su obsesión no pudo retenerlo; no podía hacerlo; era inconcebiblemente indigno de confianza pues estaba más allá del lenguaje... El Pasaje está allí, ahora y para siempre... Su narcisismo es tan inquebrantable como exclusivo. Barolo murió cerca de la fecha de inauguración del edificio. Palanti retornó a Italia y con el tiempo abandonó la arquitectura. 
1 Dante Alighieri. La Divina Commedia (Ilustraciones de Gustavo Doré), Eugenio Camerini. Milán. 1867

Canto XIII

Troppa è più la paura ond'è sospesa

l'anima mia del tormento di sotto,

che già lo 'ncarco di là giù mi pesa.

2 Que fue vestido de mujer por la madre Tetis y mandado a la corte de Licomedes para que no participase en la Guerra de Troya.

3 Ritratto allegorico di Dante, di Agnolo Bronzino, (1530). De Wikipedia https://it.wikipedia.org/wiki/ File:Dante03.jpg (imagen de domino público).

4 La Divina Comedia (Purgatorio 1, 130-132).

5 Es importante destacar que el esquema de Aristóteles fue también popular entre los islámicos y hebreos medievales; «inteligencias» se las asoció con los ángeles de la tradición bíblica por Avicena (siglo XI), Algazel, Isaac y Maimónides, y la identificación de la «fuerza motriz de cada esfera» con un ángel fue elaborada por Tomás de Aquino (siglo XIII). Este último auto tuvo gran influencia en Dante Alighieri.

6 El persa Abul'l-Abbas Ahmad ibn Muhammad ibn Kathir al-Farghani (805 - 880, ناغرفلا ريثك نب دمح), conocido como Alfraganus o Alfergani, nació en Fergana, Sogdiana (actual Uzbekistán). Fue uno de los astrónomos persas más célebres del siglo IX. El Monte

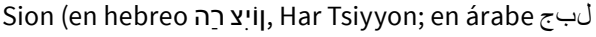
نوي:, Jabel Sahyoun) es una colina de Jerusalén. Se encuentra fuera de las murallas de la ciudad vieja.

7 Beatriz mostrará a Dante el mundo espiritual de las Esferas, enumerando la entera jerarquía de ángeles.

«E se tanto secreto ver proferse mortale in terra, non voglio ch'ammiri; ché chi 'I vide qua sú gliel discoperse con altro assai del ver di questi giri».

«Y si tanta verdad secreta pudo revelar un mortal, tú no te asombres; pues quien aquí la vio pudo mostrársela, junto a otras verdades de estos círculos».

8 Dante Alighieri, Convivio 33, 5 y Paraíso IV, 49 mencionan al Timeo de Platón, y en capítulo 6 de su obra El Convivio, Dante expone el esquema cósmico según el cual a cada esfera corresponde una de las jerarquías angélicas expuestas por el pseudo Dionisio. Es muy interesante advertir que en el capítulo 5 , el poeta advierte sobre los dos modos diferentes de explicación que proporcionó Aristóteles en sus obras Sobre el cielo y Metafísica. Ver: D. Alighieri, Convivio 1995, [introd., notas y coment. de Piero Cudini. Garzanti. (Milán, $5^{\mathrm{a}}$ ed).

9 Ver: James Dauphiné, 1984.Le cosmos de Dante. (París: Les Belles Lettres, Paris).
10 Riccardo Guerri, 1988. Schemi riassuntivi. (Buenos Aires: Dante Alighieri). ISBN 950-9089-39-7 (Riccardo Guerri, Florencia 1922 - BsAs 1997, Dr. en Jurisprudencia de la Università degli Studi di Firenze, Director de Estudios de la Dante Alighieri de BsAs).

11 http://www.wikiwand.com/it/Dante Alighieri (imagen de dominio público).

12 Miguel Asín Palacios 1961. La escatología musulmana en La Divina Comedia (Madrid : Edit. Hiperión Madrid 1961).

13 Ver R. Bossaglia, M. Cozzi, I Coppedè, Sagep, Genova 1982. También, C. Sanguineti, Scheda sobre Gino Coppedè 2007, pp. 147-151.

14 Venturini Domenico, Rossi Amilcare, 1932. Dante Alighieri e Mussolini Benito,1932.

15 Gabriele D'Annunzio (Pescara, 12 de marzo de 1863 - Gardone Riviera, 1 de marzo de 1938) principe de Montenevoso, fue un novelista, poeta, dramaturgo, militar y político italiano, símbolo del Decadentismo y héroe de guerra. Apodado «il Vate» (es decir, «el poeta profeta») ocupó una posición prominente en la literatura italiana desde 1889 hasta 1910 y, en la vida política, entre 1914 y 1924, aproximadamente.

16 Publicados en los libros: Arch. Mario Palanti, 1917, Prima Esposizione Persónate D'architettvra Nella Repvblica Argentina, (Stabilimento Grafiche Bizzolo \& Pizzio, Milano y Arch.) ; Mario Palanti, 1917, Cinqve Anni di Lavoro, 1924 (Milán : Casa Editrice Dárte Bestetti \& Tumminelli).

17 El General Juan Domingo Perón también fue miembro terciario de la Orden Franciscana, en la cual recibió todos los Sacramentos a lo largo de su vida.

18 Publicados en los libros: Arch. Mario Palanti, 1917, Prima Esposizione Persónate D'architettvra Nella Repvblica Argentina, (Stabilimento Grafiche Bizzolo \& Pizzio, Milano y Arch.) ; Mario Palanti, 1917, Cinqve Anni di Lavoro, 1924 (Milán : Casa Editrice Dárte Bestetti \& Tumminelli).

19 En el cristianismo, un obispo (del latín episcopus; en griego غ́пі́бкопоऽ, 'vigilante', 'inspector', 'supervisor' o 'superintendente') es un fiel que recibe el liderazgo de supervisar a los pastores o sacerdotes, según el caso, de un territorio determinado.

20 Tras un nostálgico encuentro de Eneas con su padre Anquises, él le explica la estructura del Cosmos y predice el gran linaje de emperadores que crearán un imperio de Paz que llegará al otro lado de la Elíptica, es decir al Hemisferio Austral.

21 El Campanile di Giotto, de la iglesia Santa María del Fiore, catedral de Florencia, tiene igual en sus medallones del primer nivel donde muestra la «Caída original y la Redención por el trabajo», y en él, figuras simbólicas de los planetas, las virtudes, las artes liberales y los sacramentos. 
22 Ver «Danteum de Terragni» por Carlos Hilger. Revista Astrágalo: Revista Cuatrimestral Iberoamericana. septiembre 2017.

23 Ver «Danteum de Terragni» por Carlos Hilger. Revista Astrágalo: Revista Cuatrimestral Iberoamericana. septiembre 2017.

24 Bertrand du Pouget (en italiano Bertrando del Poggetto) (Castelnau-Montratier, c. 1280 - Villeneuvelès-Avignon, 3 de febrero de 1352) fue un diplomático y cardenal francés.

25 Trattatello in laude di Dante Giovanni Boccaccio 1362 https://it.wikisource.org/wiki/ Trattatello in laude di Dante.

26 «La diffusione della biografia di Boccaccio sortì i suoi effetti. Nel 1373 i cittadini di Firenze avanzarono istanza ai priori per l'organizzazione di una serie di pubbliche lezioni sulla Commedia» (Reynolds, p. 430).

27 Medicei Leone X... Leone Tettoni - Francesco Saladini, Teatro araldico, ovvero Raccolta generale delle armi ed insegne gentilizi e delle piu illustri e nobili casate, vol. 7, Milán, Claudio Wilmant, 1847, SBN IT\ICCU \ TO0\0902625.

28 «Della scoperta delle ossa di Dante»; Ravenna (Italia). Consiglio municipale; Cavagna Sangiuliani di Gualdana, Antonio, conte, 1843-1913, former owner. IU-R; Conti, Romolo, 1908.

29 Cuando en 1810 Napoleón ordenó la supresión de las órdenes religiosas. 